\title{
Numerical modeling the bonding mechanism of HVOF sprayed particles
}

\author{
S. Kamnis ${ }^{\text {a }}$ S. Gu ${ }^{\text {a,* }}$, T.J. Lu $^{\text {b }}$, C. Chen ${ }^{\mathrm{b}}$ \\ a School of Engineering Science, University of Southampton, Highfield, Southampton SO17 1BJ, United Kingdom \\ ${ }^{\mathrm{b}}$ MOE Key Laboratory for Strength and Vibration, School of Aerospace, Xi'an Jiaotong University, Xi'an 710049, PR China
}

\section{A R T I C L E I N F O}

\section{Article history:}

Received 29 January 2009

Received in revised form 2 April 2009

Accepted 15 May 2009

Available online 21 June 2009

\section{Keywords:}

Thermal spray

HVOF

Impact

Bonding

Coating formation

\begin{abstract}
A B S T R A C T
During high velocity oxy-fuel (HVOF) thermal spraying, most powder particles remain in solid state prior to the formation of coating. A finite element (FE) model is developed to study the impact of thermally sprayed solid particles on substrates and to establish the critical particle impact parameters needed for adequate bonding. The particles are given the properties of widely used WC-Co powder for HVOF thermally sprayed coatings. The numerical results indicate that in HVOF process the kinetic energy of the particle prior to impact plays the most dominant role on particle stress localization and melting of the particle/substrate interfacial region. Both the shear-instability theory and an energy-based method are used to establish the critical impact parameters for HVOF sprayed particles, and it is found that only WC-Co particles smaller than $40 \mu \mathrm{m}$ have sufficient kinetic and thermal energy for successful bonding.
\end{abstract}

(c) 2009 Elsevier B.V. All rights reserved.

\section{Introduction}

High velocity oxy-fuel (HVOF) thermal spraying can generate coatings with higher density, superior bond strengths and less decarburization than other thermal spray processes, which is attributed mainly to its outputs of sprayed particles with high impact velocities and relatively low peak temperatures. Powder particles, normally in the range of 5-65 $\mu \mathrm{m}$ [1], are fed into HVOF guns where they are heated and accelerated up to $1200 \mathrm{~m} / \mathrm{s}$ before deposited on the substrate. A downstream powder injection is adopted for liquid fuelled HVOF guns [2,3], where shorter particle residence times in the flame and subsequent lower particle temperatures reduce dissolution, oxidation [4] and decomposition of metal powders. The computational analysis of HVOF sprayed WC-Co particles shows that most particles are in solid state prior to impact for a typical stand-off distance of $0.32 \mathrm{~m}$ and only particles smaller than $5 \mu \mathrm{m}$ are in liquid form [5]. The impingement of liquid droplets including spreading, break-up, air entrapment and solidification has been studied and reported in [6,7], while the solid particle impact and its subsequent bonding mechanism has not been well understood. A practical problem for HVOF coating is the difficulty to achieve a deposition rate larger than $60 \%$. Given the rising costs of materials such as WC-Co powders, even a small increase of deposition efficiency could lead to a substantial saving for the coating industry. It is therefore important to understand the bonding mechanism between particle and substrate, i.e., the

\footnotetext{
* Corresponding author. Tel.: +44 1212043582; fax: +44 1212043683.

E-mail address: s.gu@soton.ac.uk (S. Gu).
}

intricate interaction with kinetic/thermal energy and particle inter-locking for an effective control of the process.

The operation of cold spraying in certain extent exhibits resemblance to the HVOF coating, while particles gain more kinetic energy with less heat input. The experimental observation [8-11] and numerical models [12-14] of the deformation of solid particles from cold spraying show that bonding is a result of extensive plastic deformation and related phenomena at the impact interface. Quantitative analyses [12-14] on the relationship between the deposition efficiency and particle impact velocities indicate a critical particle velocity for successful bonding, i.e., solid particles below the critical velocity rebound from the substrate causing densification and abrasion similar to shot pinning method while particles above this critical velocity deform plastically and bond on the substrate. Thermal softening from the plastic deformation needs to overcome the strain-hardening effect occurring in a thin region at the contact interface which causes thermal-plastic shear-instability $[15,16]$ and is attributed to bonding [14]. In addition to the above shear-instability theory, an energy model-based method [17] has been proposed to use adhesion and elastic energies to derive the critical bonding velocities. The modeling approaches have been applied to cold spraying to establish the effect of process parameters on the deposition efficiency. However, in the context of HVOF where both thermal and kinetic energies are present, quantitative studies on particle impact parameters influencing the bonding process are scarce. Only recently modeling of HVOF sprayed SS 316 powder is reported [25]. Considering the low deposition rate $(<50 \%)$ for HVOF sprayed particles, more systematic study needs to be followed in this direction to underpin the bonding mechanism between the particles and substrates. 
This paper aims to use computational models to examine the bonding mechanism of HVOF thermal spray coatings and to establish the critical impact velocities using both the shear-instability and the energy-based methods. The popular WC-Co powders are selected and the particle parameters prior to impact are taken from the CFD in-flight particle models reported in [5]. As a first step to model the solid impact process of HVOF coating, the particles are treated as sphere in the present investigation. In a future study, the model will be refined to consider the irregular morphology of WC-Co powder.

\section{Model development}

The solid impact dynamics are analyzed by using the commercially available finite element (FE) solver ABAQUS/explicit [18]. The model accounts for strain-hardening, thermal softening and heating due to frictional and plastic dissipation. Due to the very small particle size and time scale (nanoseconds) related to HVOF particle impact process, heat transfer from particle to substrate and vice versa can be effectively neglected so that heating is assumed to be adiabatic $[12,14]$. The material properties are summarized in Table 1 . The elastic response of the material follows a linear elasticity model which is adequate for most impact cases. The plastic response of WC-Co is assumed to comply with the widely used Johnson-Cook plasticity model [19] as follows:

$$
\begin{aligned}
\tau & =\left(A+B \bar{\gamma}_{p}^{n}\right) \cdot\left(1+C \ln \frac{\dot{\gamma}}{\dot{\gamma}_{0}}\right) \cdot\left[1-\left(\frac{T-T_{0}}{T_{m}-T_{0}}\right)^{m}\right] \\
T & =T_{0}+\frac{\beta}{\rho c_{p}} \int \tau d \bar{\gamma}_{p}
\end{aligned}
$$

where $\bar{\gamma}_{p}$ is the average plastic shear strain; $\dot{\gamma}_{0}$ is the reference shear strain rate; $\dot{\gamma}$ is the imposed shear strain rate; $T_{0}$ is the impact temperature; $T_{m}$ is the melting temperature; $\beta$ is the work to heat conversion factor (based on the empirical assumption that $90 \%$ of the kinetic energy is dissipated to heat allowing for heat conduction within the particle); $c_{p}$ is the heat capacity; $\rho$ is the density; $A, B$, $C, m$ and $n$ are material-dependent constants taken from [24]: static shear strength, strain-hardening modulus, strain rate sensitive coefficient, thermal softening exponent and strain-hardening exponent, respectively.

For the energy-based calculations, the energy required [20,21] for the particle to bounce from the substrate is expressed as

$E_{R}=\frac{1}{2} c_{r} m_{p} u_{p}^{2}$

where $m_{p}$ and $u_{p}$ are the mass and velocity of the particle. The expression of the recoil coefficient $c_{r}$ can be found in [22] and is not shown here for brevity. The strain-hardening, thermal softening and deformation localization needed for the calculation of the recoil coefficient are provided from the Johnson-Cook plasticity model. The energy required [23] to detach a bonded particle from the substrate is given by:

$E_{A}=a \% A_{\max }$

Table 1

Material properties of WC-Co powder [24].

\begin{tabular}{ll}
\hline Density $\left(\mathrm{kg} / \mathrm{m}^{3}\right)$ & 14,000 \\
Solidus temperature $(\mathrm{K})$ & 1580 \\
Liquidus temperature $(\mathrm{K})$ & 1640 \\
Specific heat $(\mathrm{J} / \mathrm{kg} \mathrm{K})$ & 295 \\
Latent heat $(\mathrm{J} / \mathrm{kg})$ & 420,000 \\
Young's modulus (GPa) & 500 \\
Poisson's ratio & 0.27 \\
Shear strength (MPa) & 95 \\
\hline
\end{tabular}

where $A_{\max }$ is the maximum adhesion energy, and $a \%$ is the relative strength of bond between the particle and substrate which is mainly affected by particle velocity and contact temperature. Detailed expressions for the maximum adhesion energy and relative bond strengths can be found in [22].

The impact process is contained in a three-dimensional (3D) domain shown in Fig. 1. The substrate dimension is chosen to be five times larger than the particle diameter to avoid possible effects on the particle-substrate deforming zones from the boundary nodes. The substrate bottom face is constrained in all directions, while the other faces are set to free. Grid sensitivity analyses have shown that mesh size plays a dominant role on material heating and consequently to shear flow localization [14]. For this reason very fine meshes are employed for both the particle and substrate. For instance, the $40 \mu \mathrm{m}$ particle has a mesh size of $0.5 \mu \mathrm{m}$ corresponding to approximately 700,000 four-node linear tetrahedron elements. The velocity and temperature of spray particles prior to impact on the substrate are taken from the CFD in-flight particle models [5] according to the chosen diameters. The monitor node is randomly selected on the surface of the impacting particle at a location where intensive plastic deformation is expected. The monitored node as shown in Fig. 1 is used for the output of results concerning temporal evolution of temperature and flow stress.

\section{Results and discussions}

The simulation is for WC-Co particle impact on stainless stain substrate which has a uniform temperature of $300 \mathrm{~K}$. The particle parameters are varied in terms of particle diameter, impact velocity and temperature. Particles of $40 \mu \mathrm{m}$ in diameter are selected as the baseline particle in this study.

\subsection{Particle impingement}

The temperature contours from spray particles having a temperature of $800 \mathrm{~K}$ and landing at $300 \mathrm{~m} / \mathrm{s}$ and $500 \mathrm{~m} / \mathrm{s}$, respectively, are presented in Fig. 2 for selected impact times. The particle starts to deform immediately after impact, causing the formation of a crater on the substrate. In the early stage of the impingement ( $30 \mathrm{~ns}$ ), the deformation of the contact surface is evident and the crater size increases in width and height to accommodate the deformed particle as the particle penetrates deeper into the substrate. At $130 \mathrm{~ns}$, when the particle kinetic energy has fallen

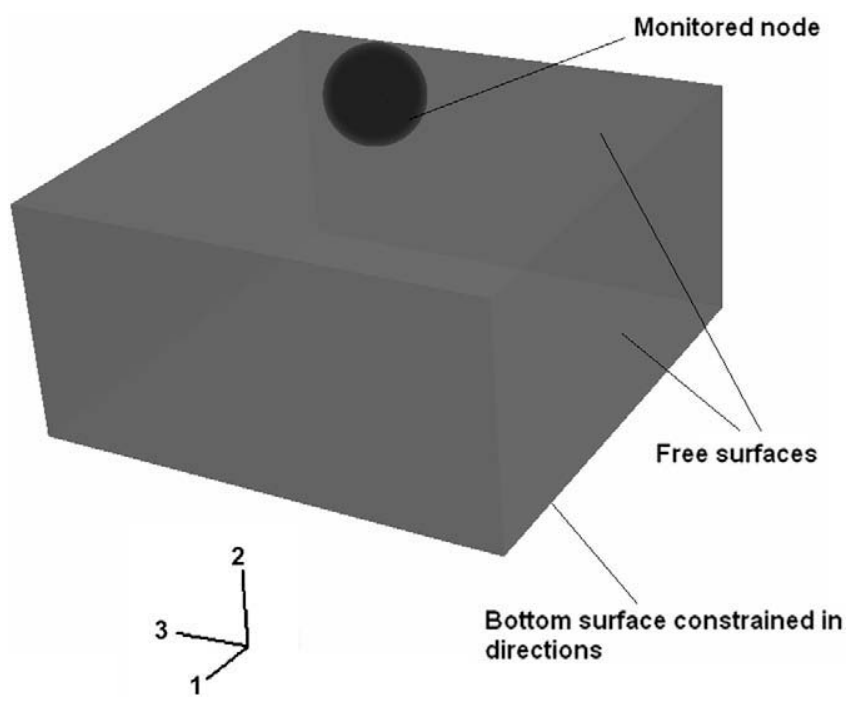

Fig. 1. Computational domain for 3D finite element model. 
Particle size: $40 \mu \mathrm{m}$

Temperature: $800 \mathrm{~K}$

mpact Velocity: $300 \mathrm{~m} / \mathrm{s}$

Impact Velocity: $500 \mathrm{~m} / \mathrm{s}$
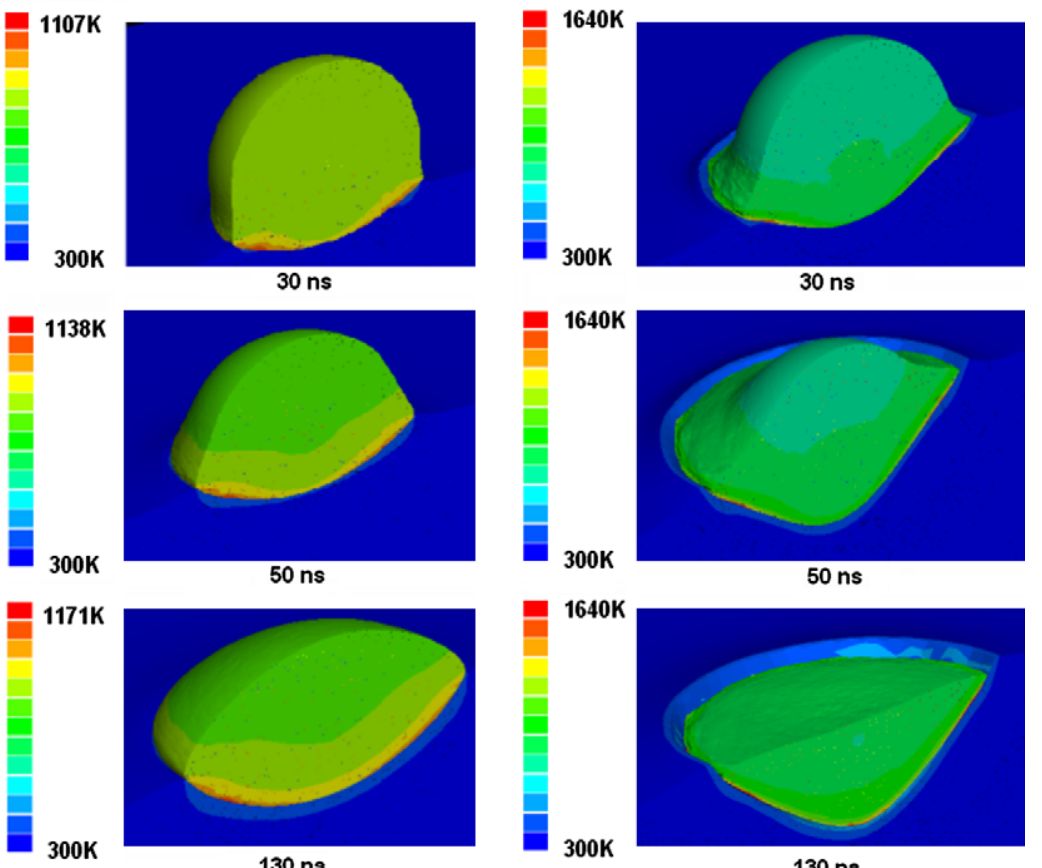

Fig. 2. Particle temperature contours for $40 \mu \mathrm{m}$ particle with impact temperature of $800 \mathrm{~K}$.

to zero, the particle flattens to a lens-like shape. The particle experiences extensive deformation with the maximum plastic strain scatters within the contact zone rather than concentrates at the centre point of impact. At the localized contact interface significant temperature increase is observed as a result of kinetic energy being converted to internal energy and part of it to plastic work (dissipated as heat). In this region, the temperature rises to $1171 \mathrm{~K}$ at $130 \mathrm{~ns}$. It should be noted that the particle/substrate interface (contact surface) never reaches the melting point of $1640 \mathrm{~K}$ under the impact velocity of $300 \mathrm{~m} / \mathrm{s}$. The contact surface temperatures at $130 \mathrm{~ns}$ are shown in Fig. 3, where the interfacial region for the particle is on the top and the substrate at the bottom. The results show that the temperature is not uniformly distributed over the surfaces due to different plastic strain rates. A higher temperature is observed along the highly deformed zones around the edge of the particle than that at the centre. The temperature contours on the substrate surface indicate that the temperature increase is much lower than that of the particle, which is attributed to the smaller plastic deformation experienced by the substrate during impact.

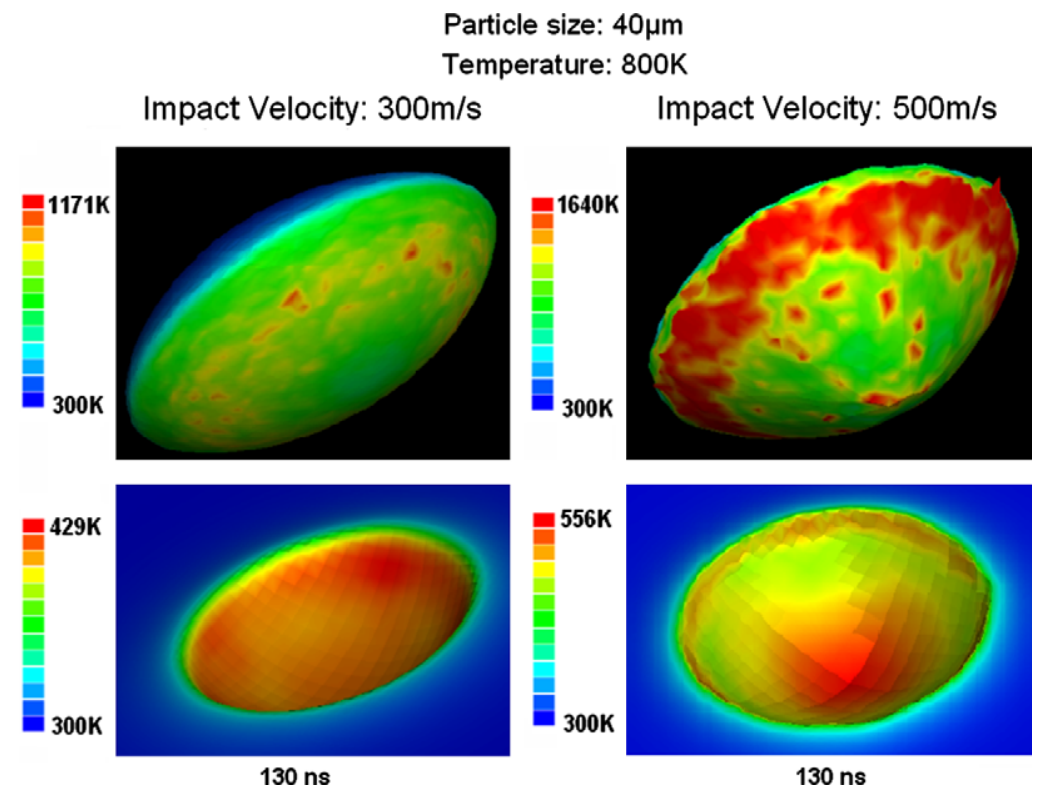

Fig. 3. Interfacial temperature contours for $40 \mu \mathrm{m}$ particle with impact temperature of $800 \mathrm{~K}$ particle at $130 \mathrm{~ns}$ (top: particle contact surface; bottom: substrate crater). 
A significant difference is observed when the particle impact velocity is increased from $300 \mathrm{~m} / \mathrm{s}$ to $500 \mathrm{~m} / \mathrm{s}$. On the right side of Fig. 2, the particle is penetrating deeper into the substrate, whilst the edges of the particle are pulled outwards forming a jet-like shape in the periphery of the contact zone. The particle is plastically deformed in greater extent and the temperature at the interface reaches the melting point $(1640 \mathrm{~K})$. The melting of the particle at $500 \mathrm{~m} / \mathrm{s}$ is more pronouncedly shown in Fig. 3 where a much larger melted area around the particle edge is clearly seen at $130 \mathrm{~ns}$. Within this melted area the deformation mechanism of the particle has changed from plastic to viscous flow. The extensive thermal softening in this region results in a low resistance of the material to shear flow. Near the melting point the material loses its shear strength and undergoes excessive deformation. The result of such viscous-type flow can be explained by Raleigh-Taylor instabilities [7] which in turn promote adhesion through mutually conforming contacting surfaces. Due to these softening effects the particle is deformed in a greater extent than the substrate, resulting in lower crater surface temperature as shown in Fig. 3 (bottom right). The temperature on the substrate interface is also increased to $556 \mathrm{~K}$ at high impact velocity of $500 \mathrm{~m} / \mathrm{s}$. The prediction of particle deformation and possible melting from high speed particles is also confirmed by results obtained with cold spraying experiments [8-11].

\subsection{Effect of particle impact velocity}

In this study, the particle remains at the impact temperature of $800 \mathrm{~K}$ while the impact velocities are varied at 300, 400 and $500 \mathrm{~m} / \mathrm{s}$. The temperature and flow stress evolution on the monitored node, which undergoes the highest amount of deformation within the particle, are shown separately in Figs. 4 and 5. The temporal development of temperature in the monitored node for velocities smaller than $500 \mathrm{~m} / \mathrm{s}$ follows the same trend as that of flow stress. The temperature reaches the melting point at the impact velocity of $500 \mathrm{~m} / \mathrm{s}$ whereas in other cases it remains well below the melting point. An increase of $100 \mathrm{~m} / \mathrm{s}$ in the impact velocity results in a temperature increase of almost $400 \mathrm{~K}$ in the critical element. For impact velocities smaller than $500 \mathrm{~m} / \mathrm{s}$, the stress profiles increase along with the impact velocity, which is attributed to the loading conditions and thermal softening effect. A significant change in stress development occurs when the impact velocity reaches $500 \mathrm{~m} / \mathrm{s}$. As the melting temperature is reached the variation of stress is characterized by instabilities and a decrease in the overall magnitude close to zero. This drop of flow stress can be explained with respect to the change of deformation mechanism from plastic to viscous. Under such conditions the shearing and heating becomes highly localized while

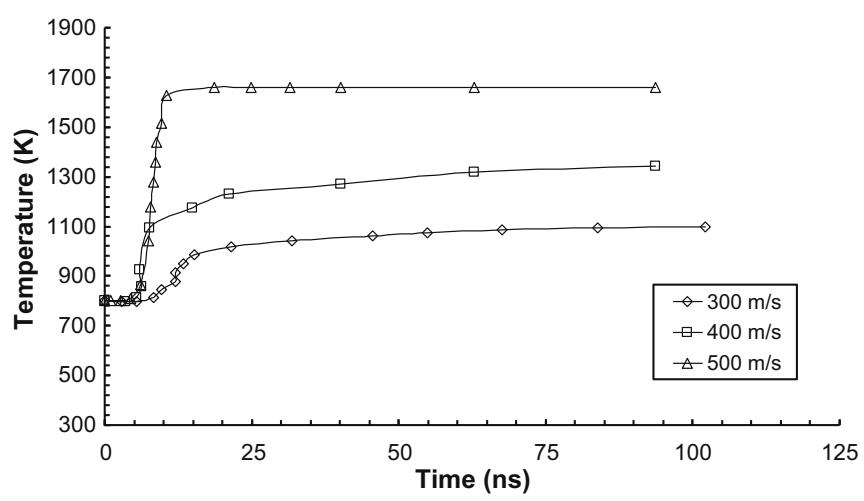

Fig. 4. Temperature evolutions at the monitor point with different impact velocities.

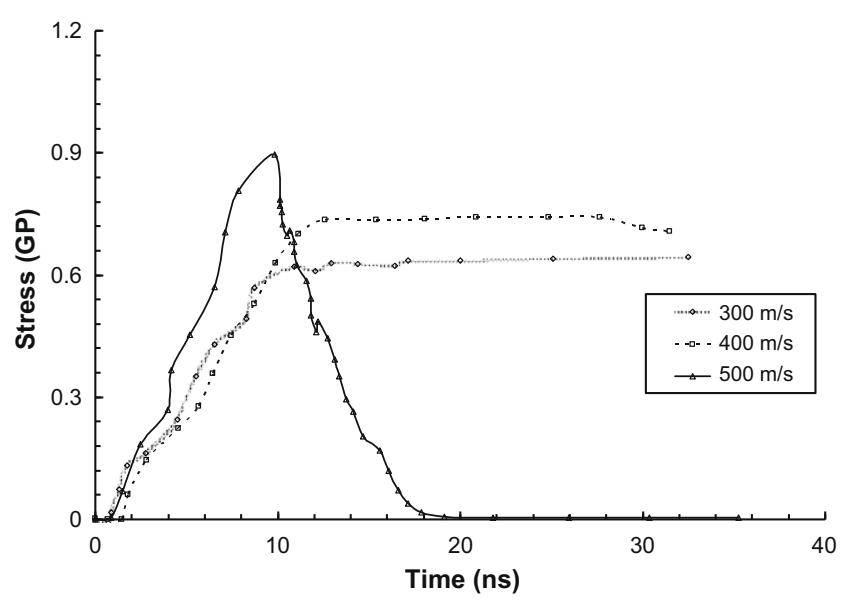

Fig. 5. Flow stress evolutions at the monitor point with different impact velocities.

the straining and heating practically stops. From the temperature plot in Fig. 4, no further heating of the material is observed under stress localization at $500 \mathrm{~m} / \mathrm{s}$. Consequently, more effective bonding of the particle on the substrate is achieved under such conditions [14].

\subsection{Effect of particle impact temperature}

Unlike cold spray, in HVOF process the particles are accelerated through momentum transfer from hot combusting gases. Apart from the kinetic energy, heat is also being transferred to the particles from the surrounding gas flow. It remains an open question whether kinetic or thermal energy is the driving force for successful particle bonding. To address this issue, different particle impact temperatures, namely $1000 \mathrm{~K}, 1200 \mathrm{~K}$ and $1300 \mathrm{~K}$, are used with the same impact velocity of $300 \mathrm{~m} / \mathrm{s}$. The effect of initial temperature on the thermal and stress behavior of the particle upon impact is shown in Figs. 6 and 7. The evolution of temperature and flow stresses follows the same pattern as described above when the impact velocity is increased gradually. Similarly, the increase of impact temperature with impact velocity fixed results in an increase of critical element temperature. The difference is that the temperature rise is proportionally increased with impact temperature, i.e., the exact amount of $300 \mathrm{~K}$ is gained by the critical element when the impact temperature increases from $1000 \mathrm{~K}$ to $1300 \mathrm{~K}$. Whereas, the increase of impact velocity from $300 \mathrm{~m} / \mathrm{s}$ to $500 \mathrm{~m} / \mathrm{s}$ contributes to an increase of $\sim 600 \mathrm{~K}$ for the critical ele-

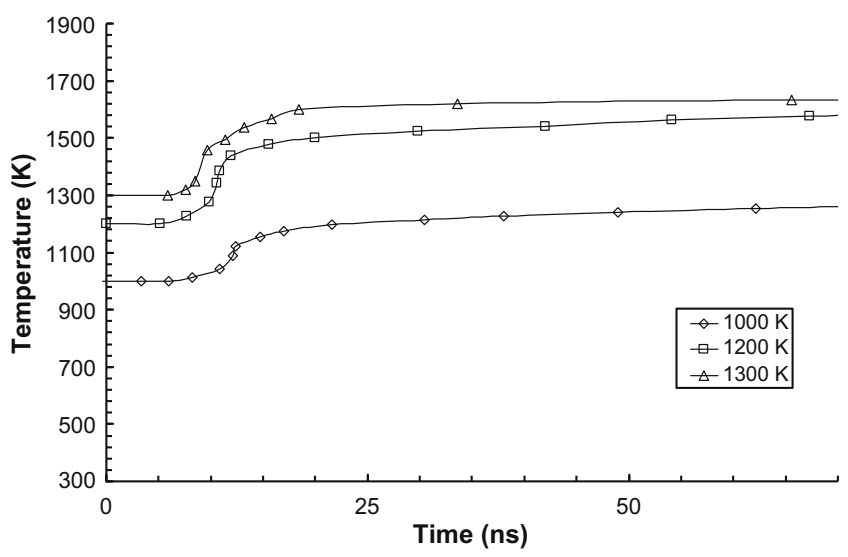

Fig. 6. Temperature evolutions at the monitor point with different impact temperatures. 


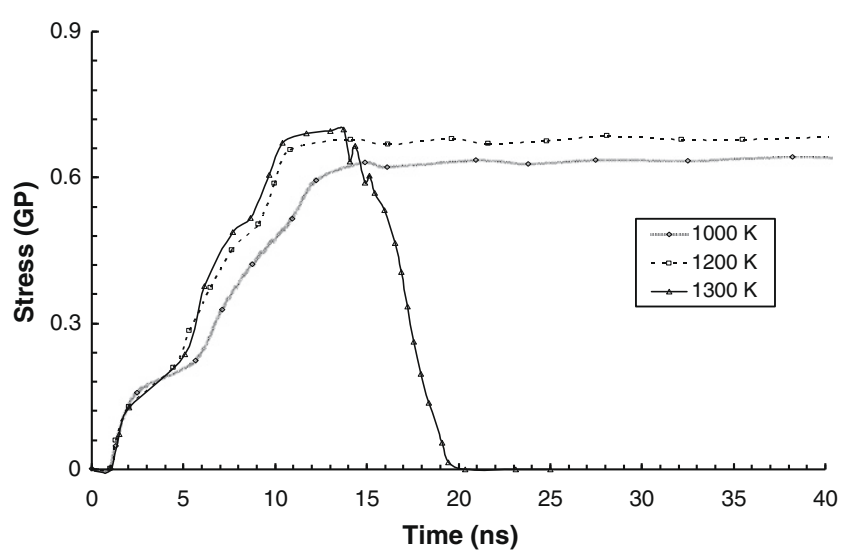

Fig. 7. Flow stress evolutions at the monitor point with different impact temperatures.

ment. These results indicate that the plastic work being dissipated to heat is not significantly altered at different particle impact temperatures. The kinetic energy being converted to heat in these cases remains the same and the difference in final critical element temperature is attributed to the impact temperature plus a constant heat for all cases from plastic work dissipation. The comparison clearly demonstrates that the kinetic energy of the particle prior to impact is playing the most dominant role on particle stress localization and melting of the interfacial region. Practically this means that to improve the quality of HVOF coatings, more attention should be paid to increasing the momentum output rather than the thermal output.

\subsection{Critical impact conditions}

The above analysis is based on $40 \mu \mathrm{m}$ particle size. In reality a wide range of powder distribution is used for thermally sprayed HVOF coatings. For this reason it is necessary to obtain information on critical impact velocities and temperatures with respect to particle size. Fig. 8 plots the critical velocity as a function of impact temperature for three particle sizes: 20,40 , and $60 \mu \mathrm{m}$. The results indicate that a proportional increase of critical velocity is required as the particle becomes larger. The points marked with $X$ represent the particle impact velocity and temperature obtained from computational fluid dynamics (CFD) models for in-flight particle

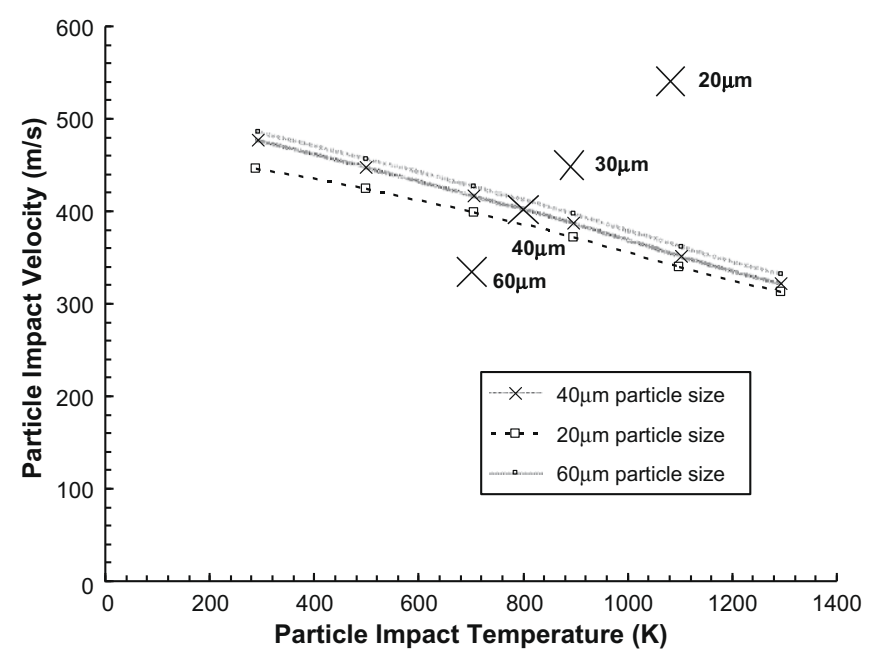

Fig. 8. Critical velocity profiles.

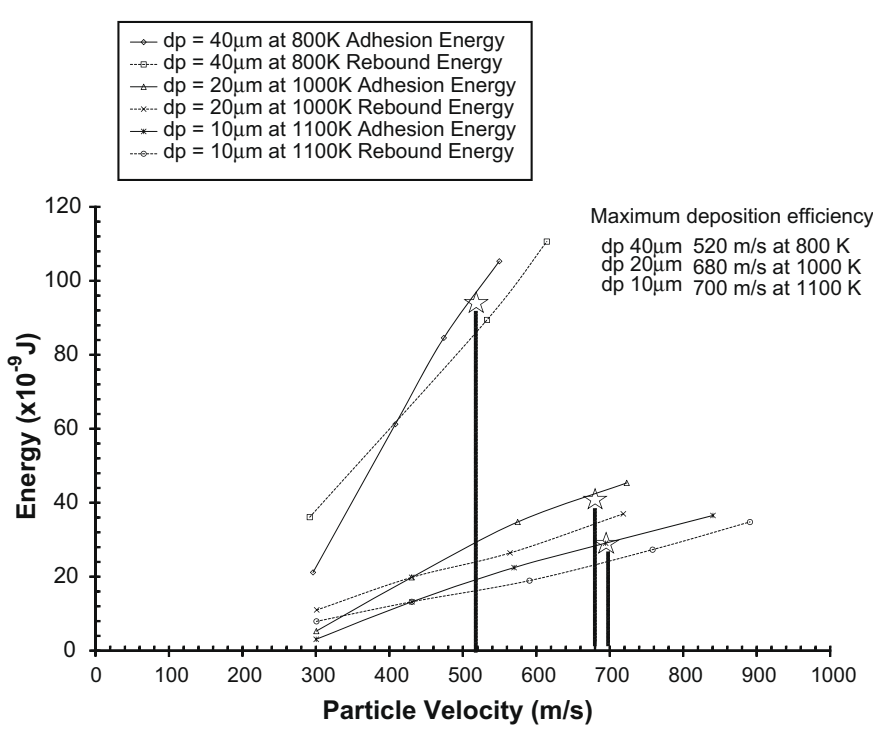

Fig. 9. Correlations for adhesion and rebound energies at different impact velocities.

dynamics from the HVOF gun [5]. For the particles located above the lines, the impact temperature and velocity are adequate to ensure bonding on the substrate. For the range of particles used, only powder sizes smaller than $40 \mu \mathrm{m}$ have enough kinetic and thermal energy for successful bonding.

Fig. 8 is created according to the bonding criterion of adiabatic shear-instability reported in [14]. An alternative method of finding the critical impact velocities for different particle sizes is by calculating the adhesion and rebound energies of the particle. A very good description and implementation of this method can be found in [22]. During impact an elastic collision takes place, followed by an elastic unloading during which the shape of the particle is recovered partially. The energy required to bounce the particle from the substrate during unloading is defined as rebound energy. Adhesion energy is defined as the energy for detaching the bonded particles from the substrate. Fig. 9 shows how the two types of energy change as a function of impact velocity. The particle is assumed to attach onto the substrate when the adhesion energy is higher than the rebound energy. For low impact velocities, the adhesion energy is lower than the rebound energy and the particle cannot be deposited. The impact velocity where the two curves intersect is the critical velocity. The optimum impact velocity for maximum deposition efficiency exists at the peak value of adhesion energy minus rebound energy. The optimum impact velocities are listed in the top right of Fig. 9. The energy-based results are in good agreement with the previous observation of critical velocity of about $450 \mathrm{~m} / \mathrm{s}$ for the $40 \mu \mathrm{m}$ particles. The results are also applicable to critical impact velocities for different particle sizes and the energy curves intersect at different velocities for different particle sizes are shown in Fig. 9.

\section{Conclusions}

A FE model has been developed to study the impingement process and bonding mechanism of thermally sprayed HVOF particles. Insightful results on the intricate interaction between plastic deformation and bonding formation are obtained. This work provides the basis for future more realistic simulation such as coating build up. In case of multiple particle impact, different results are expected for particle spreading and temperature rise. This is because the already deposited layer absorbs the kinetic energy delivered to substrate by the impacting particle, which affects particle 
temperature spreading and final splat shape. Furthermore the morphology of the surface on which particles are landing could play a dominant role on the impact dynamics. Particle rebound and void creation between the deposited layers are also possible to influence the results. The conclusions based on the current single particle simulation can be summarized as follows:

- Due to thermal softening effects the particle is deformed in a greater extent than the substrate, resulting in a lower crater surface temperature compared to that of the particle interfacial region.

- The kinetic energy of the particle prior to impact plays the most dominant role on particle stress localization and melting of the interfacial region.

- Both the shear-instability theory and the energy-based method lead to the same critical impact velocity for adequate bonding of HVOF sprayed particles.

- For the range of particles simulated only powder sizes smaller than $40 \mu \mathrm{m}$ have enough kinetic and thermal energy to result in successful bonding.

\section{Acknowledgements}

The authors gratefully acknowledge the financial support from the UK DTI Technology Programme (TP/J3019E), the UK-China Fellowships for Excellence Programme provided by the UK DIUS, the National 111 Project of China (B06024), the National Natural Science Foundation of China $(10572111,10632060)$, and the National Basic Research Program of China (2006CB601202).

\section{References}

[1] N. Zeoli, S. Gu, S. Kamnis, Int. J. Heat Mass Transfer 15-16 (2008) 4121-4131.

[2] S. Kamnis, S. Gu, Chem. Eng. Sci. 61 (2006) 5427-5439.

[3] S. Kamnis, S. Gu, Chem. Eng. Process. 45 (2006) 246-253.

[4] N. Zeoli, S. Gu, S. Kamnis, Comput. Chem. Eng. 32 (2008) 1661-1668.

[5] S. Kamnis, S. Gu, T.J. Lu, C. Chen, Comput. Mater. Sci. 43 (2008) 1172-1182.

[6] S. Kamnis, S. Gu, J. Phys. D: Appl. Phys. 38 (2005) 3664-3673.

[7] S. Kamnis, S. Gu, T.J. Lu, C. Chen, J. Phys. D: Appl. Phys. 41 (2008) 165303. 7pp.

[8] D.L. Gilmore, R.C. Dykhuizen, R.A. Neiser, T.J. Roemer, M.F. Smith, J. Therm. Spray Technol. 8 (1999) 576-586.

[9] C.J. Li, W.Y. Li, Surf. Coat. Technol. 167 (2003) 278-283.

[10] T.H. Van Steenkiste, J.R. Smith, R.E. Teets, Surf. Coat. Technol. 154 (2002) 237252.

[11] R.C. Dykhuizen, M.F. Smith, D.L. Gilmore, R.A. Neiser, X. Jiang, S. Sampath, J. Therm. Spray Technol. 8 (1999) 559-567.

[12] M. Grujicic, J.R. Saylor, D.E. Beasley, W.S. DeRosset, D. Helfritch, Appl. Surf. Sci. 219 (2003) 211-223.

[13] M. Grujicic, C.L. Zhao, W.S. DeRosset, D. Helfritch, Mater. Des. 25 (2004) 681.

[14] H. Assadi, F. Gartner, T. Stoltenhoff, H. Kreye, Acta Mater. 51 (2003) 43794394.

[15] T.W. Wright, Int. J. Plast. 8 (1992) 583-602.

[16] T.W. Wright, Mech. Mater. 17 (1994) 215-222.

[17] A.N. Paryrin, S.V. Klinkov, V.F. Kosarev, in: International Conference on Thermal Spray, ASM International, Orlando, 2003, p. 27.

[18] http://www.abaqus.com/, ABAQUS Inc.

[19] G.R. Johnson, W.H. Cook, in: Proceedings of the Seventh International Symposium on Ballistics, Netherlands, 1983, pp. 541-548.

[20] W. Kohlhofer, R.K. Penny, Int. J. Pres. Ves. Pip. 66 (1996) 333-339.

[21] R.B. Clough, S.C. Webb, R.W. Armstrong, Mater. Sci. Eng. 360 (2003) 396-407.

[22] J. Wu, H. Fang, S. Yoon, H. Kim, C. Lee, Scr. Mater. 54 (2006) 665-669.

[23] Y.V. Kurochkin, Y.N. Demin, S.I. Soldatenknov, Chem. Petrol. Eng. 38 (2002) $245-248$.

[24] E. Aldie, J.R. Johnson, Mechanical Properties at Room Temperature of Four Cermets of Tungsten Carbide with Cobalt Binder, National Advisory Committee for Aeronautics, Technical Note: 3309, Washington, USA, 1954.

[25] P. Bansal, P.H. Shipway, S.B. Leen, Acta Mater. 55 (2007) 5089-5101. 